\title{
An Action Research on a French Law Firm: Solutions for a Law Firm With IT Post-Adoption
}

\author{
Min Feng, Iaelyon, Magellan, Université de Lyon, Jean-Moulin, France \\ Driss Bourazzouq, Université Paris-Saclay, UVSQ, Larequoi, Versailles, France
}

\begin{abstract}
This study qualitatively analyzes interactional coping strategies used to manage technostress in the post-adoption stage of information technology implementation at a French legal firm. The nine strategies are participatory, collaborative, conflict resolution, bureaucratic coping (adaptation), perceived contribution to exchange, loyalty, affect, professional respect, and mutual trust. A critical perspective was applied to a longitudinal study of the intervention process. First, a problem with task distribution at the individual level affected the efficacy of perceived contribution strategies to exchange and professional enhancement. Second, a lack of creative interaction between group level colleagues undermined strategies of collaboration, mutual aid and assistance, participatory adaptation, and mutual trust. Third, a lack of digitalization commitment at the organizational level negatively affected conflict resolution and bureaucratic adjustment. Finally, an absence of loyalty and affect strategies was evident.
\end{abstract}

\section{KEYWORDS}

Bureaucratic Coping, Expectation-Confirmation Theory, Information Technology, Intervention Research, Longitudinal Study, Post-Adoption Stages, Research Intervention, Technostress

\section{INTRODUCTION}

A longitudinal case study was conducted to identify interactional coping solution (ICS) in the postadoption stage of an information technology implementation at a French legal firm. This intervention research lead by scientific observations and intervention on law firms for seven months, exchange with the stakeholder-participants at least once a week. The purpose, firstly, was to explain the effects of ICS to manage technostress in the post-adoption stages of the implementation. Then, explain the evolution of the nine international coping solution that were summarized in the previous study. The nine strategies identified were (i) participatory, (ii) collaborative, (iii) conflict resolution, (iv) bureaucratic coping (adaptation), (v) perceived contribution to exchange, (vi) loyalty, (vii) affect, (viii) professional respect, and (ix) mutual trust.

Technostress is relevant for both individuals and organizations in the context of new information system (IS) implementations and within the broader context of the omnipresence of different information and communications technology (ICT) systems. Continuity of use is a significant concept in studies involving individual users. Bhattacherjee and Lin (2015, pp. 364-373) define continuity as "long-term or sustained use of an information technology (IT) by individual users." Further, "IT acceptance and continuance are conceptually and temporally distinct behaviors, in that continuance can occur only after acceptance (first-time use)" (Bhattacherjee \& Premkumar, 2004, pp. 229-254).

DOI: $10.4018 /$ JTA.20210101.oa5

This article published as an Open Access article distributed under the terms of the Creative Commons Attribution License (http://creativecommons.org/licenses/by/4.0/) which permits unrestricted use, distribution, and production in any medium, provided the author of the original work and original publication source are properly credited. 
This first use was determined as the initial adoption of the IS and the study was anchored to continue to adopt ICS after implementation (post-adoption). This line of thought poses two questions:

R1: How do interactional coping solutions (ICS) impact technostress in the post-adoption stage?

R2: What are the evolutions of interactional coping solutions (ICS)?

\section{THEORETICAL BACKGROUND}

This study falls within the field of information systems and strategies management. However, this paper aims to provide a broader base to theoretical foundations and to incorporate analytical tools from marketing. In addition, this study is based on post-adoption. Several studies have been conducted on adoption, which have yielded many discoveries. For example, a study on the Taiwanese NHSS shows that success of an IS/IT and its adoption depends on many characteristics such as "user characteristics, organizational context, and system characteristics" (Hung et al., 2012, pp. 84-108), but also "the factors of user experience, user training, information quality, service quality, and user satisfaction have a strong positive effect on system use" (Hung et al., 2012, pp. 84-108), and that the behavior of the person with the IT also has an impact: "user attitude and facilitating conditions have a significant and negative effect" (Hung et al., 2012, pp. 84-108).

\section{The Stages Of Adoption}

Over time, the literature on adoption has focused on different variables, such as use, reuse, and continuity (Campbell et al., 2013). This trend has led to many phases of adoption, such as pre-adoption and post-adoption.

\section{Pre-Adoption}

Karahanna (1999), to give a short description of the concept of pre-adoption: pre-adoption beliefs are formed primarily based on indirect experience (affect or cognition) with IT, the objective of defining continuity of use. Thus, the behavioral intention of a person is understood by his attitude and that if he adopts a performance and efficient behavior, others will see and perceive his capacity (Pavlou, 2006). This intention is influenced by attitude (Ajzen, 1991) which "reflects an individual's positive or negative assessment of a behavior" (Pelling, 2009). suggested by Ajzen (2002): "as a perceived control over the performance of a behavior" and which relates to the level of ease of performance of the behavior and draws on old experiences and pitfalls. Veiga (2014) also specified that the more the person has had good experiences of organizational support, the more it promotes the perceived expectation of adoption and use.

The experience influences, a priori, not only the factor of perceived behavior control, but it can also make the difference between the behavioral intention model in the pre-adoption and postadoption phase.

\section{Post-Adoption}

Based on Karahanna (1999), post-adoption usagebeliefs are formed basedon past experience. Again, Kim (2009) explains that the post-adoption (continuous adoption or disruption) (Parthasarathy \& Bhattacherjee, 1998, Gupta et al., 2020) phase always focuses on a variable such as continuity of use and neglects other factors such as recommendation (dedication-based outcome) and complaint (constraintbased outcome). People will always tend to be uncertain and need to increase communication. (Katz et Tushma,1979; Van de Ven et al. 1976) to interpret its implications (Burkhardt and Brass 1990). This communication via the social network can influence his adoption decision, in particular an informational and normative influence (Karahanna, 1999). In other words, post-adoption rely more on interpersonal information (Rogers et al., 2014). 
This study focuses primarily on the post-adoption phase, and we use the ECT as a conceptual framework (Oliver, 1980b).

\section{LITERATURE REVIEW}

This study focuses primarily on the post-adoption phase, and ECT is used as a conceptual framework (Oliver, 1980).

\section{Conceptual Review ECT: Interactional coping solutions (ICS) in the post-adoption phase}

ECT has been used to extensively analyze consumer behavior after the adoption of a product or service "to measure and understand firm agility from the customer perspective" (Atapattu et al., 2016, pp. 80-108). Wolverton et al. (2020) explain that "ECT delineates a process model in which an individual compares their pre-usage expectations about a product or service to their post-usage perceptions of the product or service, to determine the extent to which their expectations are confirmed." Thus, there is a continuity of services throughout the procurement process from suppliers (Bitner et al., 2000; Chen et al., 2006).

Similarly, the "disconfirmation (or fulfillment) of expectations is a significant influence on consumer evaluations and judgments of product and brand performance" (Oliver \& Bearden, 1985, pp. 235-246). More precisely, "consumers form initial expectations about a product or service prior to initial use" (Wolverton et al., 2020). In addition, a cancellation can cause a loss of customers. Kim and Son (2009) share the same opinion: "At the end of the transaction, the consumer confirms his expectations through a purchase process of evaluation and calculation of their level of satisfaction, which affects their future loyalty online, including buy-back decisions. In this study, waiting was considered an evaluation criterion in the post-purchase phase" (pp. 49-70).

Thus, drawing on ECT theory, the following five evaluation themes were considered: (i) perceived usefulness, (ii) perceived ease of adoption, (iii) perceived appreciation, (iv) perceived quality, and (v) additional costs, when considering the satisfaction levels in the post-adoption phase of an ICS implementation. These themes provided the focus for diagnostic interviews.

\section{Perceived Usefulness (PU)}

Cho and Sagynov (2015) found that "perceived usefulness had a slightly greater effect on consumers' purchase intention to shop online than did perceived ease of use" (pp. 21-36). Perceived usefulness (a post-adoption belief) "refers to the extent to which a particular object or tool is helpful for individuals to finish a task" (Wu et al., 2020), and "the extent to which a person believes that using a particular technology will enhance her/his job performance" (Davis, 1989, pp. 319-340). Additionally, "the perceived user interface quality significantly affects the post-adoption self-efficacy and post-adoption perceived usefulness" (Gupta et al., 2020).

\section{Perceived Ease of Use-Perceived Ease of Adoption (PEA)}

Ease of use has a dissonant effect and allows us to understand the complex nature of IT as an edge factor in explaining user behavior in the context of continuous IT use (Thong et al., 2006). "Consumers would compare their pre-use perceptions of ease-of-use, based on general beliefs or own/vicarious experiences with digital technologies" (Joo et al., 2017, pp. 83-90).

Gefen and Straub (2000) argue that perceived ease will not affect the adoption of IT because they believe that perceived ease does not have inherent links to the product or service itself. On this basis, we assume that the perceived facility does not directly influence the adoption performance of ICS and that it cannot determine whether ICS is an applicable and adequate policy to address the problem of managing technostress. 


\section{Perceived Quality (PQ)}

Marketers and business leaders are realizing that to retain their customers and grow their businesses, they need to provide high-quality services (Dabholkar, 2000). "Users invest more with an M-wallet after the initial adoption only when it minimizes their cognitive load during consumption, and the perceived user interface quality is one such mechanism" (Chatterjee \& Bolar, 2019, pp. 859-869).

\section{Perceived Enjoyment - Perceived Appreciation (PA)}

Davis (1989) defines perceived enjoyment as a measure by which the use of a computer system is perceived as personally pleasing, regardless of the instrumental value of the technology. We consider the use of IS or ICT as something fun and enjoyable or, in any case, an element that allows better productivity for a company. When it comes to customer satisfaction, there is also a "relationship structure for indicating shopping enjoyment (a type of flow experience) and rational responses as two mediators to the target of customer satisfaction from personal and technological drivers" (Rose et al., 2012, pp. 308-322).

\section{Additional Costs (AC)}

Change costs are defined as "the costs that customers associate with the process of changing from one supplier to another" (Burnham et al., 2003, pp. 109-126). Change costs refer to customer costs related to change, renewal, and implementation. According to Park et al. (2014), these are additional costs after the adoption of an IS, change of supplier, or new implementation.

\section{METHODOLOGY AND GENERAL APPROACH TO RESEARCH}

This study employs the intervention research (IR) method. This methodological approach aims to create knowledge through an interaction between the researchers and the practitioners within the firm. The reasons for choosing this method and its contribution to organizational change have been highlighted as follows.

\section{Intervention Research (IR)}

Merini and Ponté (2008) explain that "Intervention research (IR) as action research (AR) is above all a research on action, carried out indirectly in action, action for perspective" (pp. 77-95). Additionally, this, "falls within a triple perspective: describe, explain, and transform the research subject to get to know it better" (Krief \& Zardet, 2013, pp. 211-237). "People undertaking action inquiry may employ the same tools and methods as researchers do for theory building, systems thinking or causal analysis in one form or another" (Chevalier \& Buckles, 2019).

Most AR work is based on Lewin's work in the 1950s (Dubost \& Lévy, 2002; Krief \& Zardet, 2013). This study utilizes IR to assess the efficacy of ICS in managing technostress in the postadoption stage of an IT implementation.

\section{Longitudinal Single Case Study and Intervention Research}

A longitudinal study puts the researcher-intervener at the center of the intervention project for a relatively long duration, which makes it possible to study the evolution of complex phenomena over time (Van de Ven \& Huber, 1990)

Additionally, the present study established detailed activity schedules over seven months, alternating between laboratory and scientific observation at least once a week within the firm (see Table 1).

\section{The Intervention Path}

This path consisted of problematizing, preparation, evaluation, improvement, and validation. 
Problematizing: After the project launch, the authors started identifying the perception of problems, concerns, and expectations of the participants, based on the five evaluation themes (perceived usefulness, perceived ease of adoption, perceived appreciation, perceived quality, and cost). Compared to the ICS implementation, each participant gave their opinion and expectations on ICS implementation. The possible problems assimilated were then considered and solutions or improvements were suggested.

Preparation: This stage consisted of an intervention provision and a pre-assimilation of the next steps and periods to be carried out. Each intervention and decision was determined and tested, which was consistent for each period of intervention.

Assessment: This step concerned gathering data from observations, interviews, or secondary sources that allowed the authors to obtain direct and indirect opinions of the participants, and to identify possible malfunctions in the process.

Improvement: Based on participant feedback, changes were made to the intervention processes or assessment criteria.

Validation: Data were built by several round trips, modifications, and improvements that were representative.

\section{The Method of Analysis In Intervention Research (Ir)}

The path of analysis was demonstrated by theme, sub-theme, witness phase, key idea, mirror effect, "not said" expert opinion, and strength of idea.

\section{Key Ideas}

A key idea is an expression that summarizes a problem. Participating researchers invite stakeholderparticipants to express illustrations based on their feelings (Locke, 2001). Software like NVivo or Segese can build these fundamental ideas.

This process of identifying themes, constructing ideas, and clarifying links allows researchers to formulate the hierarchy of the mirror effect that qualitatively structures the information in the five evaluation themes of ICS. See the model below.

\section{Data Collection}

With reference to Table 1, the data collection carried out in the second period required waiting for the ICS policy, and the one carried out in the third period required reflecting on the performance and dysfunction of the ICS policy. During the data collection period, the authors encountered difficulties that were, first and foremost, related to the strict work schedule in the legal field. Sometimes the participants (Table 2) did not have time to answer questions; this was particularly true of senior lawyers who had busy schedules and court appearances with clients.

\section{Data Analysis}

As mentioned above, "research-intervention methods have a threefold perspective: to describe, explain, and transform the object of research, to know it better" (Savall \& Zardet, 1996). We focused on “... building a resolutely transformative research-intervention method" (Savall et al., 2019, pp. 147-167). In this research, the stage of description is interpreted using a transcription of the interviews with witness sentences, which are then explained synthetically by using key ideas and expert opinion. Finally, to better know the research object that the authors have to transform, relevant ideas are provided for interviews to improve the process and the results of the intervention project. The last step is to formulate strong ideas by grouping expert opinions

\section{Expectation via Problematizing}

The expectations of different participants, which can be positive or negative, are reflected in Table 3. 
Table 1. Schedule of the longitudinal study

\begin{tabular}{|l|l|l|l|}
\hline \multicolumn{1}{|c|}{ Period } & \multicolumn{1}{|c|}{ Steps } & \multicolumn{1}{c|}{ Duration } & \multicolumn{1}{c|}{ Goal } \\
\hline & $\begin{array}{l}\text { Initiation of the intervention } \\
\text { project }\end{array}$ & October 2018 & $\begin{array}{l}\text { Set up of ICS and information meeting in the } \\
\text { practice }\end{array}$ \\
\hline Period 1 & $\begin{array}{l}\text { Collection of data on expectation } \\
\text { for ICS policy }\end{array}$ & $\begin{array}{l}\text { Two weeks } \\
\text { later }\end{array}$ & $\begin{array}{l}\text { Know the expectations of the participants } \\
\text { about the ICS policy in place }\end{array}$ \\
\hline $\begin{array}{l}\text { Period of } \\
\text { alternation }\end{array}$ & $\begin{array}{l}\text { The authors went back and forth between the empirical field and theoretical ground, undertaking a } \\
\text { weekly meeting where an exchange of words and ideas took place. }\end{array}$ \\
\hline Period 2 & $\begin{array}{l}\text { Collection of data on the } \\
\text { performance and dysfunction of the } \\
\text { ICS policy }\end{array}$ & April 2019 & $\begin{array}{l}\text { Understand the effect of the ICS compared to } \\
\text { the expectations of the participants }\end{array}$ \\
\hline
\end{tabular}

Table 2. Respondent Profiles

\begin{tabular}{|l|l|l|}
\hline \multicolumn{2}{|c|}{ Respondent } & \multicolumn{1}{c|}{ Status } \\
\hline & Arnaud & Senior lawyer \\
\cline { 2 - 3 } & Frederic & Senior lawyer (junior lawyer until recently) \\
\cline { 2 - 3 } Law firm B & Christophe & Junior lawyer \\
\cline { 2 - 3 } & Thomas & Intern \\
\cline { 2 - 3 } & Stefania & Intern \\
\cline { 2 - 3 } & Alexandre & Junior lawyer \\
\cline { 2 - 3 } & Anne & Junior lawyer \\
\cline { 2 - 3 } & Camille & Paralegal (jurist) \\
\hline
\end{tabular}

These expectations serve not only to determine the direction of the interviews and ensure a more effective policy for the analysis, but also allow the authors to make later comparisons with the opinions collected at the improvement stage. For example, Arnaud was in favor of the ICS approach and had a positive vision for the results of the intervention:

So, we will evaluate the strategies for the steps that we will adopt. In summary, I understand that these strategies will help us to manage stress. So, the goal is to marginalize this stress, so that it is at the lowest level possible and so that the TIC (Technologies of information and communication) is used

Table 3. Expectations and interest of the participants

\begin{tabular}{|l|l|l|}
\hline \multicolumn{1}{|c|}{ Participants } & \multicolumn{1}{c|}{ Expectations-ICS post-adoption } & \multicolumn{1}{c|}{ Points of Interest and/or disquiet } \\
\hline Arnaud & Rather positive & $\begin{array}{l}\text { Establishment of an adequate policy for } \\
\text { the implementation of the ICS }\end{array}$ \\
\hline Frederic & Rather positive response over time & $\begin{array}{l}\S \text { The time required to obtain ICS results } \\
\S \text { The long-term effectiveness of its results }\end{array}$ \\
\hline Christophe & Requirement of strategic coherence & \\
\hline Thomas & A vision with a little apprehension & Undifferentiated point of view on ICS \\
\hline Stefania & Rather positive & ICS efficiency levels \\
\hline
\end{tabular}


as efficiently as possible. So, it is easy, but it depends on how we manage it. (Arnaud, discussing his expectations of individual strategies)

First, it should be noted that most companies rely heavily on ICT, which may even provide a competitive edge. However, there is stress associated with the use of ICT. Second, the participant thinks that it is necessary to implement coping strategies to minimize this stress and maximize technological advantages. Finally, customs and individual strategies should not be overlooked. Support, whether provided professionally or by family, ensures proper implementation of the ICS. So, for Arnaud, coping policies will be required to manage the effects of technostress.

Another respondent, Frederic, discusses the need for time in the evaluation process:

We will not be able to have an answer without time. My expectations are positive concerning the strategy itself since we must always be optimistic, but only time will be able to show us if there will be less technostress. (Frederic)

Our preliminary observation of Frederic's point of view is that he is ambivalent about the implementation. At first glance, he thinks that ICS offers useful solutions and that the approach may be feasible. However, at the same time, concerns arise, particularly the questions: "How long will it take to get the results of the ICS? Moreover, will it be useful in the long run?" In summary, a positive expectation for the strategy but a desire for a long-term observable result is expressed: "It is, first of all, an alignment of the use of the IS with the different actors" (Christophe).

Thomas expressed his vision with some apprehension. He thought that the ICS should be viewed with an undifferentiated point of view. By viewing the ICS point by point, the nine strategies cannot represent the whole result. For example, according to Thomas, a bureaucratic strategy cannot work. According to his experience, the initiative does not sufficiently manage technostress, individually or collectively, because according to him his firm has a very distant hierarchy. Therefore, not all the employees in his firm would want to work by being authors of collective initiatives.

"The strategy will not detract from my accountability or my working conditions. If it is effective, it will interest me, and it will help me to counter (a little) what you call technostress" (Stefania). Stefania has a positive expectation about the coping strategy and a motivation to fight against technostress. Nevertheless, she remains modest regarding her expectations from the results of the ICS. She wonders if the strategies can lower technostress and at what level they can be effective.

\section{Themes and Sub-themes Within Participant Statements}

For example, the following sentence indicates the working condition: "There, I share my desktop with my colleagues in an open office, but it has a good view." The participant believes that his office is well placed, which relates to one of the sub-themes, notably the layout and arrangement of the premises. This means that the working condition is considered an essential element that can negatively or positively influence the ease of adoption of the ICS. A similar pattern can be seen in a sentence regarding the perceived quality of the work: "Yes, I have a busy work schedule, and a large number of files to manage; inevitably, the adoption of ICS will be of lower quality."

\section{Qualitative Dysfunction: Production of an Expert Opinion}

In the paragraph below, the authors have established a diagnosis of the dysfunction of the practice in an intervention approach to managing technostress. Expert opinions were grouped thematically, were constructed using mirror effects, and revealed what was unsaid. To give external validation to expert opinions, information was collected and information meetings (approximately one per fortnight) were used to communicate the various opinions and collective views. Most of the time, these expert 
opinions were recognized by participants, even if sometimes, the validation was implicit. Then, the key ideas were formulated to introduce improvement projects. In general, the diagnosis made by the participating researcher was virtually confirmed by the participants from the practice; this means that they had experienced inadequacies and disadvantages in the firm, which allowed for improvement.

\section{Identification of the Expert Opinion Through the Mirror Effect and Revealing What was Unsaid}

\section{Extract From a Main Idea.}

Main ideas: The programming of activities is considered challenging to carry out; there is concern about change, addiction to the computer system, and different areas of expertise.

Mirror effect: Except for the scheduling of activities that are considered difficult to carry out, the other disruptive factors related to time management are disputed, such as anxiety about change and addiction to computer systems. These latter points of view were mentioned in the sub-theme of safety and nuisance factors, under working conditions. This reappearance demonstrates the importance of these two considerations.

Unsaid: The authors' observation here mainly concerns a different area of expertise, the lack of skill alignment, and how different tools are used.

Key ideas: The programming of activities is considered difficult to carry out.

"It is difficult under the current conditions to adopt the various policies quickly and easily" (PA).

"When things are done well, we will have set up an environment favorable to the adoption of our new tools and, therefore, to the improvement of our information systems."

Key ideas: Concern about change.

"Many people do not like change, and I view change with some apprehension." (PA)

Key ideas: Addiction to the computer system.

"Which, however, will allow us to work in better conditions, especially regarding our computer system." (PA)

\section{Results: Formulation of Main Ideas and Improvements}

From the above observations, the expert opinion by ICS was identified to distinguish the main ideas that were classified into three major themes of dysfunction for the firm linked to the intervention approach - individual, group, and organization, in a summary of key ideas and expert opinion. Finally, to improve the intervention, the expectations collected from the various stakeholder-participants from the beginning of the analysis were accounted for.

\section{Results at the Individual Level: An Inefficient Distribution of Tasks}

The link between expert opinions and ICS reveals that the perceived contribution to exchange and professional development is mentioned at the level of the individual. Other concerns relate to a lack of efficiency, waste of time, the slowdown in production, inefficient planning, and the realization of projects. Competence and expertise allude to the issue of self-worth.

The practice faces the problem of a decrease in work efficiency due to time constraints. The organization members work individually; this mode of work generates difficulty for the contribution of individuals to the work, whether it is the quality or the quantity of the tasks carried out by each member. Thus, this contribution is linked not only to the will to work but also to individual competence.

The firm works on a hierarchy, according to title, which does not necessarily value the work of each person within their area of expertise. For example, senior lawyers take on files with the potential for high financial gain, even when the case does not necessarily fall within their areas of expertise. Trainees are often responsible for the most complex tasks (e.g., filing and replying to e-mails, administrative tasks, maintaining and managing customer relations, and contacting different parties by electronic means). The stakeholder-participants are the people most affected by technostress, which 
in the present study's IR were the firm trainees. The trainees' tasks do not seem to be complicated. However, limited expertise on the part of the trainees can cause complications (e.g., errors in the classification or prioritization of e-mails). Similarly, legal documents were drawn up by secretaries who have limited legal powers. This resulted in files being reassigned and reprocessed by junior lawyers or jurists. This round trip of the file causes a significant waste of time.

The division of the organization's tasks was highlighted as an area for improvement as poor distribution of tasks resulted in decreased work efficiency. This also increased the difficulty of managing the present study's IR. Thus, the efficient distribution of tasks seemed to be urgent.

\section{Results at Group Level: Lack of interaction Between Colleagues}

Task management, interaction between colleagues, and well-being at work are connected to collaboration, mutual aid and assistance, participatory coping, and mutual trust. A motivating work environment seems to give rise to increased interactive behavior between employees. Thus, a positive working atmosphere can lead to strengthened mutual trust between colleagues. However, a lack of cooperation and weak interaction leads to insufficient information sharing, initiative-taking, or collective interest.

As observed by the authors, the firm operates hierarchically, according to expertise. For example,

Arnaud said, "They know that I want to operate like this, and they make do with it. Especially those who are below me rarely admit it." This creates a distance between colleagues. Besides, the firm does not have enough employee welfare facilities. Therefore, employees lack space for exchange and communication. The employees of the firm operate under time constraints and the senior lawyers frequently change location. Jurists have difficulty assigning priority to cases, especially since the priority scale is based on financial reports, resulting in a lack of criteria for sorting and classifying files.

A lack of interaction between colleagues does not facilitate timely or effective completion of work. The authors' recommendations, to further the development of the firm and conclude the intervention analysis, are the provision of a social location and a flatter, more horizontal hierarchical structure.

\section{Organizational Level: Lack of Commitment to Legal Digitalization}

Two categories of ICS have been diagnosed at the organizational level: conflict resolution and bureaucratic accommodation. These two points seem to emphasize the attachment to ICT, such as the complexity of internal software.

People faced with this difficulty have understood, in my opinion, that the judicial work is moving towards digitalization and that there is no choice. We are forced to adapt to the various IT tools and still work internally... [However] each firm can adapt its internal software a little bit according to requirements or needs.

This dependence on ICT also increases technostress. We found that the firm employees spent substantial time working on computers, sometimes even during meetings. The participants understood that they are part of this process of digitalizing legal information. The objective is to move toward a zero-paper policy. However, there are uncertainties due to technological changes. The fear of not mastering such software, or of being replaced by a recruit who has a better mastery of the new software (techno-insecurity), was expressed.

In the context of the digitalization of the firm, there is a lack of rigor evident in the technological benchmarking. In the face of technological change, participants must be prepared for change, mentally and technically. In this case, problems were perceived regarding the lack of adequate training and hierarchical support. In addition, the cost minimization strategy was questioned. This seems to contradict the firm's digitalization policy. The present study's findings indicate that implementation of a policy and training on technological change should be priorities for the firm. 


\section{Expectations for Improvement}

To meet the expectation of Christophe, who thought that employee behavior was one of the key elements in assessing the effect of the intervention, the authors brought the participants together by setting up an interactive and communicative environment. Christophe testified that, "We promote interactions, even positive and productive interactions; we have an autonomous and open management model, which promotes the implementation of ICS."

In the beginning, Stefania was interested in the level of effectiveness of the ICS, and she questioned the positive effects of the ICS approach. Cost and time issues were raised. During the second stage of her interview, she seemed to be less worried, saying that this investment in the ICS would be beneficial in the long term.

There is an incidence of cost increase, but we can say that cost increase is a short-term increase since it is an investment, or at least a trial, that will generate a cost for a short period, but which can be very beneficial in the long term.

Stefania was convinced that intervention in the long-term could have a positive effect in managing technostress.

It is difficult under current conditions to adapt [to] the different tools quickly and easily.

Even if our intervention tries to set up an environment of intervention as dynamic as possible, nevertheless, the organization is under a condition of budgetary restriction. In a short time and the short term, the effect of the intervention in the ICS station may not be evident.

Thomas preferred to observe the nine ICS with an undifferentiated perspective and to treat the strategies individually.

During a second interview, the authors first explained clearly what the nine ICS were; then, an interview guide was drawn up based on themes and sub-themes. The participants were questioned on the five factors of ECT theory. The authors were careful to analyze the effects of the nine ICS individually. Unfortunately, they could not intervene on the subject of individual behavior. For example, in keeping with his initial complaint, Thomas retained an unfavorable view of the initiative: "Often, I delete them; I do not delete them thoughtlessly, without reading them."

Frederic's initial point of interest was the setting up of an adequate ICS policy. The authors implemented policies that facilitated the interventions; for example, information meetings twice a month to provide an opportunity for discussion between the participants.

We have meetings. We see each other under the supervision of the director; some present issues or current topics and projects related to the intervention project are discussed. We have the right to give comments on our work, but the meetings are not punctual; approximately twice a month (Frederic).

Sometimes it was not possible to start meetings on time due to the lawyers' schedules. They were informed of the meeting content by electronic means. This meant that the participants could not ignore the feedback from their colleagues.

Arnaud's expectation from the intervention approach concerned, first, the time necessary to obtain results from the ICS and, second, the long-term effects of these results.

The present study's IR lasted only seven months, which did not allow for a finalized result, but the primary effects of the ICS were utilized, observed, and felt. The observation of the work will continue in a subsequent longer study, and additional research will be carried out. 


\section{Contributions and Limitations}

The limitations of the study relate to whether the results are generalizable to other fields. The authors have detailed an explanation for the specific context of technostress, which can be applied to other research areas. This could generate or require modifications. This study was carried out in a law firm where a hierarchical relationship was observed, with some participants lacking legal expertise. These factors can affect the performance of the ICS. However, this analysis would need to be substantiated by additional studies. In spite of this, the study's contribution is huge. It is rare that studies are conducted with law firms in management sciences and especially in IT/IS management. In particular, considering the current challenges of coping strategies during the different interactions linked to IT, the study brings different adaptation strategies to help law firms in responding to the current digitalization process in the legal field.

\section{Conclusion}

Regarding research question one, first, there is a problem with the distribution of tasks at the individual level, which is detrimental to the performance of the strategies for the perceived contribution to exchange and professional development. Second, there is a lack of notably creative interaction between colleagues at the group level, which could undermine the strategies of collaboration, mutual aid and assistance, participatory coping, and mutual trust. Finally, a lack of commitment to the digitalization process is evident at the organizational level, which harms conflict resolution and bureaucratic coping.

Concerning research question two, to begin the IR process, improvements were made to the procedure based on participant expectations and the authors' observations. First, the authors explained that they were in the post-adoption phase of the ICS in the context of the study, which was to manage technostress. A clear description and explanation of the ICS was provided during the interviews. The structure of the interview guide was mentioned in the first information meeting. The objective was to give a clear vision of our intervention.

Second, there was an attempt to unite the participants by setting up an interactive, dynamic, and communicative environment for the analysis. Regarding the implementation of information exchange policies, a means of communication between the participants was provided. This study was subject to budgetary restrictions and time constraints. With limited means and time in the medium and long term, it is possible that the effects of the intervention post-ICS implementation were not apparent in the short term. The effects of the ICS are predicted to be more observable in the long term. The authors will maintain contact with the firm with the aim of undertaking a follow-up study.

Third, the stakeholder-participants were informed whenever a change was made in the study procedure, with a view to gradual improvement. Sometimes, a lack of communication seemed to be the main hindrance to the intervention itself, the bureaucratic strategy, collaboration and mutual help, participative actions, or mutual trust.

Informed by ECT theory, the different themes and sub-themes were linked to create an analysis grid. This combination of methods ensured the validation of the study. It was observed that ICT dependence is repetitive in different themes and sub-themes, and this dependence is often accompanied by a concern about change. These cognitive invoices had a significant effect on the results of the analysis of ICS in the post-adoption phase. Conversely, a hierarchical relationship currently characterizes the firm. A lack of legal expertise in specific areas was also expressed. Both factors can affect the efficacy of the ICS.

\section{ACKNOWLEDGMENT}

This research received no specific grant from any funding agency in the public, commercial, or notfor-profit sectors. 


\section{REFERENCES}

Ajzen, I. (1991). The theory of planned behavior. Organizational Behavior and Human Decision Processes, 50(2), 179-211. doi:10.1016/0749-5978(91)90020-T

Ajzen, I. (2002). Perceived behavioral control, self-efficacy, locus of control, and the theory of planned behavior 1. Journal of Applied Social Psychology, 32(4), 665-683. doi:10.1111/j.1559-1816.2002.tb00236.x

Al-Ansari, M. A., \& Alshare, K. (2019). The impact of technostress components on the employees satisfaction and perceived performance: The case of Qatar. Journal of Global Information Management, 27(3), 65-86. doi:10.4018/JGIM.2019070104

Atapattu, M., Sedera, D., Ravichandran, T., \& Grover, V. (2016). Customers' view of agility: The expectationconfirmation theory perspective. Asia Pacific Journal of Information Systems, 26(1), 80-108. doi:10.14329/ apjis.2016.26.1.80

Bhattacherjee, A., \& Lin, C. P. (2015). A unified model of IT continuance: Three complementary perspectives and crossover effects. European Journal of Information Systems, 24(4), 364-373. doi:10.1057/ejis.2013.36

Bhattacherjee, A., \& Premkumar, G. (2004). Understanding changes in belief and attitude toward information technology usage: A theoretical model and longitudinal test. Management Information Systems Quarterly, 28(2), 229-254. doi: $10.2307 / 25148634$

Bitner, M. J., Brown, S. W., \& Meuter, M. L. (2000). Technology infusion in service encounters. Journal of the Academy of Marketing Science, 28(1), 138-149. doi:10.1177/0092070300281013

Burkhardt, M. E., \& Brass, D. J. (1990). Changing patterns or patterns of change: The effects of a change in technology on social network structure and power. Administrative Science Quarterly, 35(1), 104-127. doi: $10.2307 / 2393552$

Burnham, T. A., Frels, J. K., \& Mahajan, V. (2003). Consumer switching costs: A typology, antecedents, and consequences. Journal of the Academy of Marketing Science, 31(2), 109-126. doi:10.1177/0092070302250897

Campbell, D. E., Wells, J. D., \& Valacich, J. S. (2013). Breaking the ice in B2C relationships: Understanding pre-adoption e-commerce attraction. Information Systems Research, 24(2), 219-238. doi:10.1287/isre.1120.0429

Chatterjee, D., \& Bolar, K. (2019). Determinants of mobile wallet intentions to use: The mental cost perspective. International Journal of Human-Computer Interaction, 35(10), 859-869. doi:10.1080/10447318.2018.1505697

Chen, A. N., Sen, S., \& Shao, B. B. (2006). Strategies for effective web services adoption for dynamic e-businesses. Decision Support Systems, 42(2), 789-809. doi:10.1016/j.dss.2005.05.011

Chevalier, J. M., \& Buckles, D. J. (2019). Participatory action research: Theory and methods for engaged inquiry (2nd ed.). Routledge. doi:10.4324/9781351033268

Cho, Y. C., \& Sagynov, E. (2015). Exploring factors that affect usefulness, ease of use, trust, and purchase intention in the online environment. International Journal of Management \& Information Systems, 19(1), 21-36. doi:10.19030/ijmis.v19i1.9086

Dabholkar, P. A., Shepherd, C. D., \& Thorpe, D. I. (2000). A comprehensive framework for service quality: An investigation of critical conceptual and measurement issues through a longitudinal study. Journal of Retailing, 76(2), 139-173. doi:10.1016/S0022-4359(00)00029-4

David, A. (1999). Logic, epistemology and methodology in management sciences. AIMS Conference, 1-23.

David, A. (2000). Logique, méthodologie, et épistémologie en sciences de gestion: Trois hypothèses revisités. Les nouvelles fondations des sciences de gestion. Editions Vuibert, Collection FNEGE.

Davis, F. D. (1989). Perceived usefulness, perceived ease of use, and user acceptance of information technology. Management Information Systems Quarterly, 13(3), 319-340. doi:10.2307/249008

Dubost, J., \& Lévy, A. (2002). Action research and intervention. Vocabulary of psychosociology. References and Positions, 391-416. 
Gupta, A., Yousaf, A., \& Mishra, A. (2020). How pre-adoption expectancies shape post-adoption continuance intentions: An extended expectation-confirmation model. International Journal of Information Management, 52, 102094. doi:10.1016/j.jinfomgt.2020.102094

Hung, W., Chang, L., \& Lee, M. (2012). Factors influencing the success of National Healthcare Services information systems: An empirical study in Taiwan. Journal of Global Information Management, 20(3), 84-108. doi:10.4018/jgim.2012070104

Joo, Y. J., Park, S., \& Shin, E. K. (2017). Students' expectation, satisfaction, and continuance intention to use digital textbooks. Computers in Human Behavior, 69, 83-90. doi:10.1016/j.chb.2016.12.025

Karahanna, E., Straub, D. W., \& Chervany, N. L. (1999). Information technology adoption across time: A crosssectional comparison of pre-adoption and post-adoption beliefs. Management Information Systems Quarterly, 23(2), 183-213. doi:10.2307/249751

Katz, R., \& Tushman, M. (1979). Communication patterns, project performance, and task characteristics: An empirical evaluation and integration in an R\&D setting. Organizational Behavior and Human Performance, 23(2), 139-162. doi:10.1016/0030-5073(79)90053-9

Kim, S. S., \& Son, J. Y. (2009). Out of dedication or constraint? A dual model of post-adoption phenomena and its empirical test in the context of online services. Management Information Systems Quarterly, 33(1), 49-70. doi: $10.2307 / 20650278$

Krief, N., \& Zardet, V. (2013). Analysis of qualitative data and intervention research. Research in Management Sciences, 2, 211-237. doi:10.3917/resg.095.0211

Locke, K. (2001). Grounded theory in management research (SAGE series in management research). Sage Publications.

Merini, C., \& Ponté, P. (2008). Intervention research as a way of questioning practices. Knowledge (Beverly Hills, Calif.), 1, 77-95. doi:10.3917/savo.016.0077

Moisdon, J. C. (2010). Evaluating organizational change using the intervention research approach. The example of the impact of T2A. Revue Française des Affaires Sociales, 1, 213-226. doi:10.3917/rfas.101.0213

Novak, T. P., Hoffman, D. L., \& Yung, Y. F. (2000). Measuring the customer experience in online environments: A structural modeling approach. Marketing Science, 19(1), 22-42. doi:10.1287/mksc.19.1.22.15184

Oliver, R. L. (1980). A cognitive model of the antecedents and consequences of satisfaction decisions. JMR, Journal of Marketing Research, 17(4), 460-469. doi:10.1177/002224378001700405

Oliver, R. L., \& Bearden, W. O. (1985). Disconfirmation processes and consumer evaluations in product usage. Journal of Business Research, 13(3), 235-246. doi:10.1016/0148-2963(85)90029-3

Park, J. G., Park, K., \& Lee, J. (2014). A firm's post-adoption behavior: Loyalty or switching costs? Industrial Management \& Data Systems, 114(2), 258-275. doi:10.1108/IMDS-06-2013-0259

Parthasarathy, M., \& Bhattacherjee, A. (1998). Understanding post-adoption behavior in the context of online services. Information Systems Research, 9(4), 362-379. doi:10.1287/isre.9.4.362

Pavlou, P. A., \& Fygenson, M. (2006). Understanding and predicting electronic commerce adoption: An extension of the theory of planned behavior. Management Information Systems Quarterly, 30(1), 115-143. doi: $10.2307 / 25148720$

Pelling, E. L., \& White, K. M. (2009). The theory of planned behavior applied to young people's use of social networking web sites. Cyberpsychology \& Behavior, 12(6), 755-759. doi:10.1089/cpb.2009.0109 PMID:19788377

Rogers, E. M., Singhal, A., \& Quinlan, M. M. (2014). Diffusion of innovations. Routledge.

Rose, S., Clark, M., Samouel, P., \& Hair, N. (2012). Online customer experience in e-retailing: An empirical model of antecedents and outcomes. Journal of Retailing, 88(2), 308-322. doi:10.1016/j.jretai.2012.03.001

Savall, H., \& Zardet, V. (1996). La dimension cognitive de la recherche-intervention: La production de connaissances par interactivité cognitive. Revue internationale de systémique, 10, 157-189. 
Savall, H., \& Zardet, V. (Eds.). (2008). Mastering hidden costs and socioeconomic performance. IAP.

Savall, H., Zardet, V., Bonnet, M., \& Cappelletti, L. (2019). Valoriser la recherche par l'expérimentation en entreprise-Cas du modèle de management socio-économique. Revue française de gestion, 45(284), $147-167$. 10.3166/rfg.2019.00373

Taylor, S., \& Todd, P. A. (1995). Understanding information technology usage: A test of competing models. Information Systems Research, 6(2), 144-176. doi:10.1287/isre.6.2.144

Thong, J. Y., Hong, S. J., \& Tam, K. Y. (2006). The effects of post-adoption beliefs on the expectation-confirmation model for information technology continuance. International Journal of Human-Computer Studies, 64(9), 799-810. doi:10.1016/j.ijhcs.2006.05.001

Van de Ven, A. H. (1976). A framework for organization assessment. Academy of Management Review, 1(1), 64-78.

Van de Ven, A. H., \& Huber, G. P. (1990). Longitudinal field research methods for studying processes of organizational change. Organization Science, 1(3), 213-219. doi:10.1287/orsc.1.3.213

Veiga, J. F., Keupp, M. M., Floyd, S. W., \& Kellermanns, F. W. (2014). The longitudinal impact of enterprise system users' pre-adoption expectations and organizational support on post-adoption proficient usage. European Journal of Information Systems, 23(6), 691-707. doi:10.1057/ejis.2013.15

Wolverton, C. C., Hirschheim, R., Black, W. C., \& Burleson, J. (2020). Outsourcing success in the eye of the beholder: Examining the impact of expectation confirmation theory on IT outsourcing. Information \& Management, 57(6), 103236. doi:10.1016/j.im.2019.103236

Wu, I. L., Chiu, M. L., \& Chen, K. W. (2020). Defining the determinants of online impulse buying through a shopping process of integrating perceived risk, expectation-confirmation model, and flow theory issues. International Journal of Information Management, 52, 102099. doi:10.1016/j.ijinfomgt.2020.102099 